\title{
Stability Improvement of a Hybrid DFIG-Based and PMSG- Based Offshore Wind Farm fed to a SG-Based Power System Using a STATCOM
}

\author{
Li Wang*, Dinh-Nhon Truong \\ Department of Electrical Engineering National Cheng Kung University, Tainan City 70101, Taiwan
}

\begin{abstract}
This paper presents the stability-improvement results of a synchronous generator (SG)-based one-machine infinite-bus (OMIB) system with a hybrid doubly-fed induction generator (DFIG)-based and permanent-magnet synchronous generator (PMSG)-based offshore wind farm (OWF) using a static synchronous compensator (STATCOM). The operating performance of the studied PMSG-based OWF is simulated by an equivalent PMSG driven by an equivalent wind turbine (WT) while an equivalent DFIG driven by an equivalent WT through an equivalent gearbox is used to simulate the operating characteristics of the DFIG-based OWF. The hybrid OWF is connected to the point of common coupling (PCC) of the SG-based OMIB system through an undersea cable and an underground cable. The proposed STATCOM is connected to the PCC to supply the required reactive power to the SG-based power system. A frequency-domain approach based on a linearized system model using eigenvalue technique and a time-domain scheme based on a nonlinear system model subject to various disturbance conditions are both utilized to examine the effectiveness of the proposed control scheme. It can be concluded from the simulation results that the proposed STATCOM is capable of offering adequate damping characteristics to stabilize the studied OMIB system under various operating conditions.
\end{abstract}

Keywords: Offshore wind farm, permanent-magnet synchronous generator, doubly-fed induction generator, static synchronous compensator, stability.

\section{Introduction}

Renewable energy is one of the hottest issues in the whole world today due to the fast and huge consumption of fossil fuels. Some academic researchers have devoted to high-capacity offshore wind turbine generators (WTGs) connected to onshore substation through undersea cables. Currently, wind doubly-fed induction generators (DFIGs) [1] and wind PMSGs [2] have been widely used in highcapacity offshore wind farms (OWFs). Modular PMSG for variable speed wind turbines was proposed and multiple single-phase outputs were separately rectified to obtain a smooth dc-link voltage [2]. The dynamic model based on small-signal stability of a wind turbine (WT) with a direct-drive PMSG with its power converters and controllers was proposed in [3]. A new interconnecting method for two or more PMSG-based wind turbine generators used in a wind farm was proposed in [4], and the proposed scheme required only one externally commutated inverter and only one DC-link. A small-signal 47th-order analytical model for representing the operating characteristics of a direct-drive PMSG connected to AC grids of widely varying strength and very weak grids was explored in [5]. A variable-speed WT-PMSG connected to power grid through a fully controlled frequency converter has the reactive-power control ability to offer required reactive power of the fixed speed WT generators connected in series or parallel to

\footnotetext{
* Manuscript received July 10, 2012; revised August 19, 2012.

Corresponding author. Tel.: +886-6-2757575 ext. 62361; fax: +886-6-2763883; E-mail address: liwang@mail.ncku.edu.tw.
} 
its terminals [6]. The control strategy of a hybrid wind farm containing a large number of induction machine (IM)-based WTGs and very few number of PMSG-based WTGs to compensate the reactive power requirement of the IM during faults and mitigate power fluctuations during wind gust was proposed in [7]. An integration of a generator-side three-switch buck-type rectifier and a grid-side Zsource inverter as a bridge between the PMSG and the grid was proposed for a PMSG-based WTG while the experimental validation and simulation studies were carried out to examine the effectiveness of the proposed scheme [8]. A simple coordinated control of DC-link voltage and pitch angle of a PMSG-based wind energy conversion system to smooth wind power fluctuations was proposed [9].

Regarding the use of STATCOM for power-system stability improvement, stability enhancement of power systems using STATCOMs and the damping controller design of STATCOMs were presented in [10]. A variable-blade pitch of a wind energy conversion system and design of an output feedback linear quadratic controller for a STATCOM to perform mechanical power control and voltage control under different operating conditions were studied in [11]. Controller design and system modeling for quick load voltage regulation and suppression of voltage flicker using a STATCOM were explored in [12]. A novel D-STATCOM control algorithm for enabling separate control of both positive- and negative-sequence currents was proposed [13]. Dynamic characteristics of a power system with a STATCOM and a static synchronous series compensator (SSSC) through digital simulations were compared in [14]. The applications of a STATCOM for damping torsional oscillations of a series-capacitor compensated AC system were shown in [15]. Characteristics of using PSS, static VAR compensator (SVC) and STATCOM for damping undesirable inter-area oscillations of a power system were compared in [16].

This paper is organized as follows. System configuration and mathematical models of the studied system are introduced in Section 2. Eigenvalue results of system dominant modes as well as comparative transient responses of the studied system subject to a severe fault are described in Section 3 and 4, respectively. Finally, specific important conclusions of this paper are drawn in Section 5.

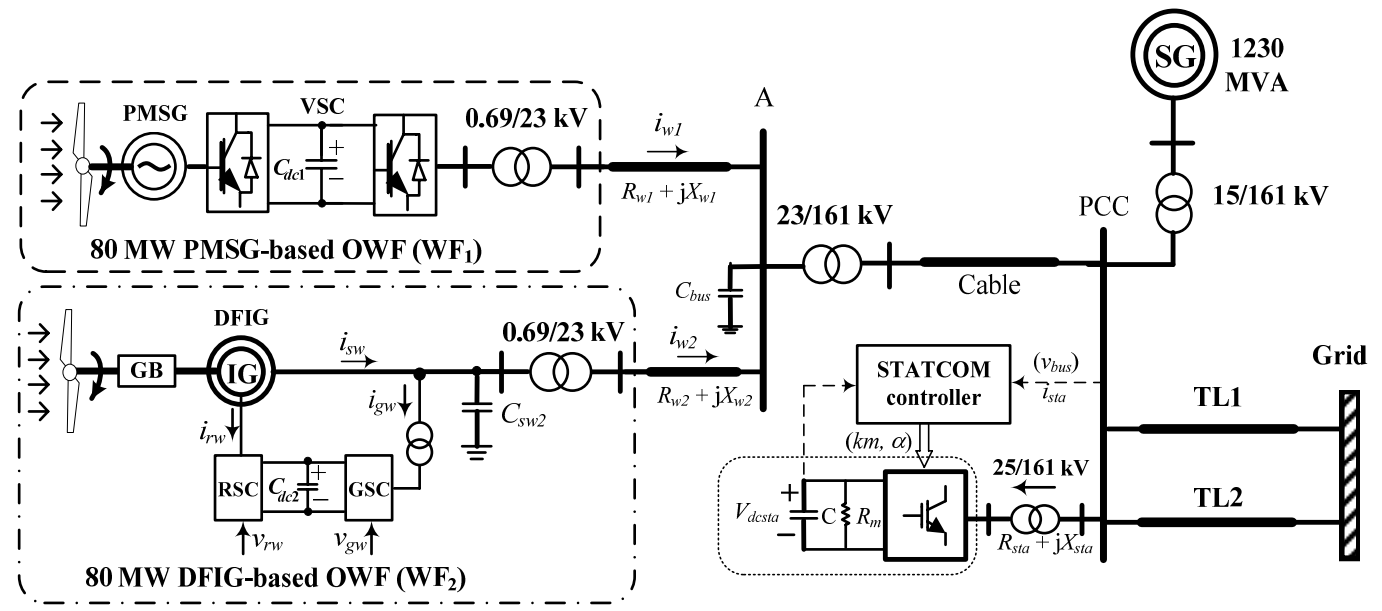

Fig. 1. Configuration of the studied SG-based OMIB system containing a PMSG-based OWF and a DFIG-based OWF with a STATCOM

\section{System Configuration}

Fig. 1 shows the configuration of the studied SG-based OMIB system containing the hybrid PMSGbased and DFIG-based OWF with a STATCOM of \pm 50 -MVAR. The 80 -MW PMSG-based OWF (WF $\left.{ }_{1}\right)$ is represented by an equivalent aggregated variable-speed wind turbine (VSWT) driven an equivalent aggregated PMSG that is fed to bus $A$ through a back-to-back power converter, a step-up transformer of $0.69 / 23 \mathrm{kV}$ and an undersea cable. The 80-MW DFIG-based OWF $\left(\mathrm{WF}_{2}\right)$ is represented by an equivalent aggregated VSWT with an equivalent gearbox driven an equivalent aggregated DFIG that is fed to bus $A$ through a step-up transformer of $0.69 / 23 \mathrm{kV}$ and an undersea cable. The equivalent capacitance $C_{b u s}$ is 
connected to the common bus $A$ that is fed to the point of common coupling (PCC) of an onshore SGbased OMIB system through an offshore step-up transformer of $23 / 161 \mathrm{kV}$, undersea cables, and underground cables. The studied SG of 1230 MVA is fed to the PCC through a step-up transformer of $15 / 161 \mathrm{kV}$ and transmission lines, and the PCC is also connected to a large power grid through two parallel transmission lines (TL1 and TL2) [17]. The proposed STATCOM is connected to the PCC through a step-down transformer of $25 / 161 \mathrm{kV}$ for damping improvement of the studied SG subject to the power fluctuations of the hybrid OWF during wind-speed variations.

\section{A.1. Wind turbine model and mass-spring-damper model}

The wind turbine model in this paper can be referred to $[14,15]$ with the cut-in, rated, and cut-out wind speeds for the wind DFIG (wind PMSG) are selected as $4(3) \mathrm{m} / \mathrm{s}, 14(13) \mathrm{m} / \mathrm{s}$, and $24(23) \mathrm{m} / \mathrm{s}$, respectively.

The two-inertia reduced-order equivalent mass-spring-damper model of the WT coupled to the rotor shaft of the studied wind DFIG through a gearbox is applied in this study [16]. This model can also be applied to the mass-spring-damper model of the WT coupled to the rotor shaft of the studied wind PMSG except the employed parameters. The effect of the equivalent gearbox (GB) between the WT and the DFIG has been included in this model [17].

\section{A.2. DFIG model and operation of power converters}

Fig. 2 shows the one-line diagram of each wind DFIG driven by a WT through a gearbox $[2,18]$. The stator windings of the DFIG are directly connected to the low-voltage side of the $0.69 / 24-\mathrm{kV}$ step-up transformer while the rotor windings of the DFIG are connected to the same $0.69-\mathrm{kV}$ side through a rotorside converter (RSC), a DC link, a grid-side converter (GSC), a step-up transformer, and a connection line. For normal operation of a DFIG, the input AC-side voltages of the RSC and the GSC can be effectively controlled to achieve the aims of simultaneous output active-power and reactive-power control [19]. The detailed operation of the RSC and GSC can be referred to [20].

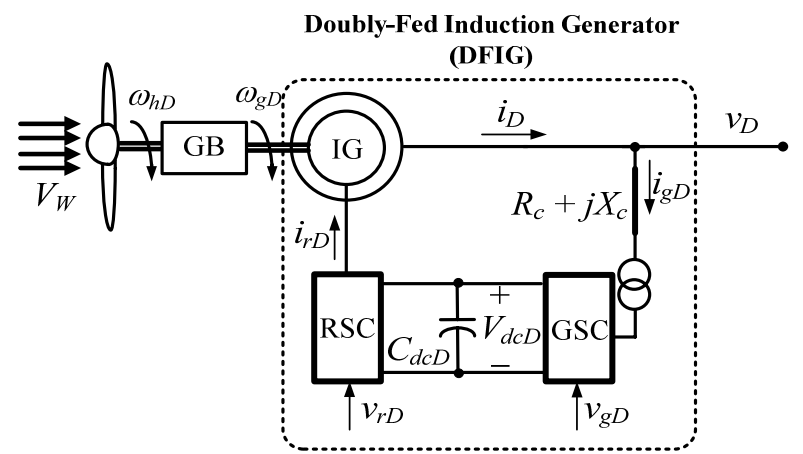

Fig. 2. One-line diagram of each wind doubly-fed induction generator

\section{A.3. PMSG Model and Operation of Power Converters}

The $d-q$ axis equivalent-circuit model of the studied wind PMSG can be expressed by $[13,16]$

$$
v_{q S P}=-r_{s P} i_{q S P}+\frac{p \psi_{q P}}{\omega_{b}}+\frac{\omega_{r P}}{\omega_{b}} \psi_{d P}, \quad v_{d s P}=-r_{s P} i_{d s P}+\frac{p \psi_{d P}}{\omega_{b}}-\frac{\omega_{r P}}{\omega_{b}} \psi_{q P}
$$

in which

$$
\psi_{q P}=-\left(X_{m q P}+X_{l s P}\right) i_{q S P}=-X_{q P} i_{q S P}, \quad \psi_{d P}=-\left(X_{m d P}+X_{l s P}\right) i_{d s P}+X_{m d P} i_{m P}^{\prime}=-X_{d P} i_{d s P}+X_{m d P} i_{m P}^{\prime}
$$

where $\Psi$ is the pu flux linkage, $v_{S P}$ is the pu stator-winding voltage, $i_{S P}$ is the pu stator-winding current, $X_{m P}$ is the pu magnetization reactance, $X_{I P}$ is the pu leakage reactance, $i_{m P}{ }_{m P}$ is the pu magnetization current, 
$\omega_{r P}$ is the pu rotational speed, and $\omega_{b}$ is the base angular speed. The input $d-q$ axis pu voltages of the VSC-converter of the wind PMSG can be expressed by, respectively.

$$
v_{\text {cond }}=k m_{\text {cond }} V_{d c P}, \quad v_{\text {conq }}=k m_{\text {conq }} V_{d c P}
$$

where $V_{d c P}$ is the DC-link voltage while $\mathrm{km}_{\text {cond }}$ and $\mathrm{km}_{\text {conq }}$ are the $d$ - and $q$-axis modulation indices of the VSC-converter, respectively. The output $d-q$ axis pu voltages of the VSC-inverter of the wind PMSG can be written by, respectively,

$$
v_{\text {invd }}=k m_{\text {inv }} \sin \left(\alpha_{\text {inv }}\right) V_{d c P}, \quad v_{\text {invq }}=k m_{\text {inv }} \cos \left(\alpha_{\text {inv }}\right) V_{d c P}
$$

where $k m_{i n v}$ and $\alpha_{i n v}$ are the modulation index and the phase angle of the VSC-inverter, respectively.

\section{A.4. STATCOM model}

The pu $q$ - and $d$-axis output voltages of the proposed STATCOM shown in Fig. 1 can be written by, respectively, [20]

$$
v_{\text {ssta }}=V_{\text {dcsta }} \cdot k m_{\text {sta }} \cdot \cos \left(\theta_{\text {bus }}+\alpha_{\text {sta }}\right), \quad v_{\text {dsta }}=V_{\text {dcsta }} \cdot k m_{\text {sta }} \cdot \sin \left(\theta_{\text {bus }}+\alpha_{\text {sta }}\right)
$$

where $v_{q s t a}$ and $v_{\text {dsta }}$ are the pu $q$ - and $d$-axis voltages at the output terminals of the STATCOM, respectively; $k m_{\text {sta }}$ and $\alpha_{\text {sta }}$ are the modulation index and phase angle of the STATCOM, respectively; $\theta_{b u s}$ is the voltage phase angle of the common AC bus, and $V_{\text {dcsta }}$ is the pu DC voltage of the DC capacitor $C_{m}$. The pu DC voltage-current equation of the DC capacitor $C_{m}$ can be described by

$$
\left(C_{m}\right) p\left(V_{\text {dcsta }}\right)=\omega_{b}\left[I_{\text {dcsta }}-\left(V_{\text {dcsta }} / R_{m}\right)\right]
$$

where $I_{\text {dcsta }}=i_{\text {qsta }} \cdot \mathrm{km}_{\text {sta }} \cdot \cos \left(\theta_{\text {bus }}+\alpha_{\text {sta }}\right)+i_{\text {dsta }} \cdot \mathrm{km}_{\text {sta }} \cdot \sin \left(\theta_{\text {bus }}+\alpha_{\text {sta }}\right)$ is the pu DC current flowing into the positive terminal of $V_{\text {dcsta }}, R_{m}$ is the pu equivalent resistance considering the equivalent electrical losses of the STATCOM, and $i_{q s t a}$ and $i_{d s t a}$ are the pu $q$ - and $d$-axis currents flowing into the terminals of the STATCOM, respectively.

The fundamental control block diagram of the employed STATCOM including a PID damping controller is shown in Fig. 3. The pu DC voltage $V_{\text {dcsta }}$ is controlled by the phase angle $\alpha_{\text {sta }}$ while the voltage $v_{\text {sta }}$ is varied by changing the modulation index $\mathrm{km}_{\text {sta }}$.
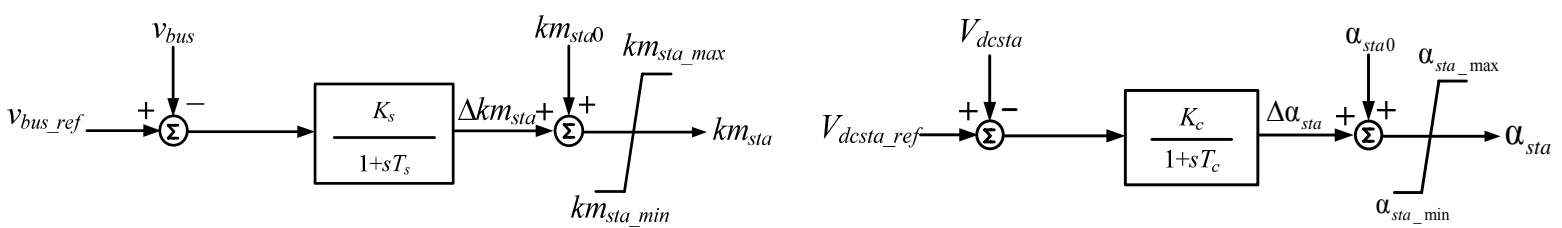

Fig. 3. Control block diagram of the employed STATCOM

\section{Eigenvalue Results}

Table 1 lists the calculated eigenvalues of the studied system under $P_{S G}$ (output active power of SG) of $0.9 \mathrm{pu}, V_{S G}$ (terminal voltage of $\mathrm{SG}$ ) of $1.0 \mathrm{pu}, P F_{S G}$ (output power factor) of 0.9 lagging, and $V_{W}$ (wind speed of two OWFs) of $12 \mathrm{~m} / \mathrm{s}$. It can be clearly seen from the results listed in Table 1 that eigenvalues $\Lambda_{1}-\Lambda_{10}$ are the modes of the SG-based OMIB system, eigenvalues $\Lambda_{11}-\Lambda_{18}$ are the modes of the PMSGbased OWF, eigenvalues $\Lambda_{19}-\Lambda_{29}$ are the modes of the DFIG-based OWF, and eigenvalues $\Lambda_{30}-\Lambda_{32}$ are the modes of the STATCOM. The dominant modes of the SG, the mechanical mode and the exciter mode, are $\Lambda_{8}$ and $\Lambda_{10}$, respectively. When the studied system is without the proposed STATCOM, it is observed from the third column of Table 1 that the mechanical mode is $-0.39197 \pm j 9.8001$ with a damping ratio of 0.039965 while the exciter mode is $-0.596 \pm j 1.6001$ with a damping ratio of 0.34905 . These two modes can be slightly moved by the proposed STATCOM connected at the PCC, and it is seen from the fifth column of Table 1 that the new mechanical mode is $-0.7627 \pm j 9.7869$ with an improved damping ratio of 0.077695 while the new exciter mode is $-0.59592 \pm j 1.6$ with a slightly reduced damping ratio of 0.34902 . 
Table 1. Eigenvalues ( $\mathrm{rad} / \mathrm{s})$ of the studied system under $P_{S G}=0.9 \mathrm{pu}, V_{S G}=1.0 \mathrm{pu}, P F_{S G}=0.9$ lagging, and $V_{W}=12 \mathrm{~m} / \mathrm{s}$

\begin{tabular}{|c|c|c|c|c|c|}
\hline No. & Mode & $\begin{array}{l}\text { Eigenvalues of the studied } \\
\text { system without STATCOM }\end{array}$ & $\begin{array}{l}\text { Damping } \\
\text { ratio }\end{array}$ & $\begin{array}{l}\text { Eigenvalues of the studied } \\
\text { system with STATCOM }\end{array}$ & $\begin{array}{l}\text { Damping } \\
\text { ratio }\end{array}$ \\
\hline$\Lambda_{1-2}$ & \multirow{10}{*}{$\begin{array}{l}\text { SG-based } \\
\text { OMIB } \\
\text { system }\end{array}$} & $-25.727 \pm j 89496$ & 0.00028746 & $-25.727 \pm j 89496$ & 0.00028746 \\
\hline$\Lambda_{3-4}$ & & $-32.393 \pm j 88736$ & 0.00036504 & $-32.393 \pm j 88736$ & 0.00036504 \\
\hline$\Lambda_{5-6}$ & & $-233.92 \pm j 10403$ & 0.02248 & $-232.97 \pm j 10422$ & 0.022347 \\
\hline$\Lambda_{7-8}$ & & $-17.61 \pm j 1087.9$ & 0.016186 & $-23.632 \pm j 2220.6$ & 0.010642 \\
\hline$\Lambda_{9-10}$ & & $-619.26,-651.83$ & 1,1 & $-620.32,-651.83$ & 1,1 \\
\hline$\Lambda_{11-12}$ & & $-0.072063 \pm j 376.99$ & 0.00019115 & $-0.072063 \pm i 376.99$ & 0.00019115 \\
\hline$\Lambda_{13-14}$ & & $-34.937,-15.979$ & 1,1 & $-34.936,-15.953$ & 1,1 \\
\hline$\Lambda_{15-16}$ & & $-0.39197 \pm j 9.8001$ & 0.039965 & $-0.7627+i 9.7869$ & 0.077695 \\
\hline$\Lambda_{17-18}$ & & $-8.9827 \pm j 10.766$ & 0.64063 & $-8.9822+i 10767$ & 0.64061 \\
\hline$\Lambda_{19-20}$ & & $-0.596 \pm j 1.6001$ & 0.34905 & $\mathbf{- 0 . 5 9 5 9 2} \pm j 1.6$ & 0.34902 \\
\hline$\Lambda_{21-22}$ & \multirow{8}{*}{$\begin{array}{c}\text { PMSG- } \\
\text { based } \\
\text { OWF } \\
\left(W_{1}\right)\end{array}$} & $-4.7032 \pm j 5.9666 \times 10^{5}$ & $7.8826 \times 10^{-6}$ & $-4.7032 \pm j 5.9666 \times 10^{5}$ & $7.8826 \times 10^{-6}$ \\
\hline$\Lambda_{23-24}$ & & $-4.504 \pm j 6.9726 \times 10^{5}$ & $6.4596 \times 10^{-6}$ & $-4.504 \pm j 6.9726 \times 10^{5}$ & $6.4596 \times 10^{-6}$ \\
\hline$\Lambda_{25-26}$ & & $-226.2 \pm j 5449.7$ & 0.041472 & $-233.39 \pm j 5392.5$ & 0.04324 \\
\hline$\Lambda_{27-28}$ & & $-23.591 \pm j 73.33$ & 0.30625 & $-23.591 \pm j 73.329$ & 0.30625 \\
\hline$\Lambda_{29-30}$ & & $-100.76 \pm j 0.30313$ & 1,1 & $-90.404 \pm j 31.581$ & 0.94405 \\
\hline$\Lambda_{31-32}$ & & $-99.14,-99.524$ & 1,1 & $-99.997,-99.528$ & 1,1 \\
\hline$\Lambda_{33-34}$ & & $-14.026,-0.70667$ & 1,1 & $-13.451,-0.70672$ & 1,1 \\
\hline$\Lambda_{35-36}$ & & $-5.4308 \pm j 3.5601$ & 0.83632 & $-5.4353 \pm j 3.6144$ & 0.83269 \\
\hline$\Lambda_{37-38}$ & \multirow{11}{*}{$\begin{array}{l}\text { DFIG- } \\
\text { based } \\
\text { OWF } \\
\left(\mathrm{WF}_{2}\right)\end{array}$} & $-4.0603 \pm j 37383$ & 0.00010861 & $-4.0603 \pm j 37383$ & 0.00010861 \\
\hline$\Lambda_{39-40}$ & & $-4.0704 \pm j 36629$ & 0.00011113 & $-4.0704 \pm j 36629$ & 0.00011113 \\
\hline$\Lambda_{41-42}$ & & $-6.1665 \pm j 375.85$ & 0.016404 & $-6.1654 \pm j 375.86$ & 0.016401 \\
\hline$\Lambda_{43-44}$ & & $-14.329 \pm j 292.08$ & 0.048998 & $-13.163 \pm j 288.03$ & 0.045652 \\
\hline$\Lambda_{45-46}$ & & $-2.5806 \pm j 49.714$ & 0.051839 & $-2.5587 \pm j 49.7$ & 0.051415 \\
\hline$\Lambda_{47-48}$ & & $-6.8918 \pm j 28.9$ & 0.23196 & $-6.8923 \pm j 28.899$ & 0.23199 \\
\hline$\Lambda_{49-50}$ & & $-14.984,-0.10285$ & 1,1 & $-14.983,-0.10285$ & 1,1 \\
\hline$\Lambda_{51-52}$ & & $-1.5439 \pm j 3.6126$ & 0.39298 & $-1.5439 \pm j 3.6126$ & 0.39298 \\
\hline$\Lambda_{53-54}$ & & $-1.6791,-10.868$ & 1,1 & $-1.6791,-10.867$ & 1,1 \\
\hline$\Lambda_{55-56}$ & & $-10.219,-8.9971$ & 1,1 & $-10.219,-8.9972$ & 1,1 \\
\hline$\Lambda_{57-58}$ & & $-8.7116 \pm j 0.59036$ & 0.99771 & $-8.7119 \pm j 0.59065$ & 0.99771 \\
\hline$\Lambda_{59-60}$ & \multirow{3}{*}{ STATCOM } & - & - & $-35.841 \pm j 910.4$ & 0.039339 \\
\hline$\Lambda_{61-62}$ & & - & - & $-100.64,-227.64$ & 1,1 \\
\hline$\Lambda_{63}$ & & - & - & -136.53 & 1 \\
\hline
\end{tabular}

\section{Transient Responses}

Fig. 4 shows transient responses of the studied system subject to a three-phase short-circuit fault at the power grid. The applied fault starts at $t=1.0 \mathrm{~s}$ and lasts for $0.1 \mathrm{~s}$. The blue lines and the red lines shown in Fig. 4 are the responses of the studied system without and with STATCOM, respectively. It can be observed from the transient responses of the SG shown in Figs. 4(a)-4(d) that the active power and reactive power of the SG have sharp peaks at $t=1.0 \mathrm{~s}$ when the system with the proposed STATCOM but the STATCOM can offer better damping characteristics to the mechanical mode to damp oscillations of the SG. The transient responses of the active power, the reactive power, and the voltage of $\mathrm{WF}_{1}$ shown in Figs. $4(\mathrm{e})-4(\mathrm{~g})$ as well as the transient responses of the active power, the reactive power, and the voltage of $\mathrm{WF}_{2}$ shown in Figs. 4(h)-4(j) also have sharp peaks at $t=1.0 \mathrm{~s}$ when the system with the proposed STATCOM but the proposed STATCOM may render better damping performance to the mechanical mode to quickly return back to steady-state values. The transient response of the reactive power of the STATCOM shown in Fig. 4(k) initially jumps to reach as high as $0.21 \mathrm{pu}$ at around $t=1.98 \mathrm{~s}$ to supply larger reactive power to support the voltage profile of the SG-based OMIB system during the faulted period and then gradually returns back to the original steady-state value. The transient response of the voltage at PCC shown in Fig. 4(1) suddenly drops to close to $0.6 \mathrm{pu}$ at $t=1.0 \mathrm{~s}$ and then quickly returns back to the steady-state value. It can be concluded from the transient simulation responses shown in Fig. 4 that the studied system with the proposed STATCOM have better damping characteristics to suppress mechanical-mode oscillations of the SG due to the applied severe fault at the power grid. 


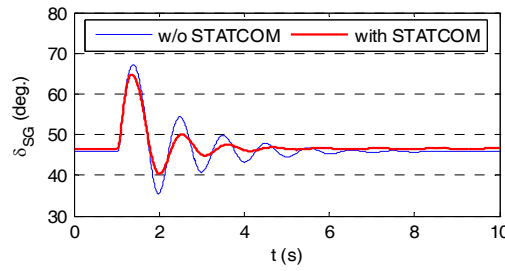

(a) $\delta_{S G}$

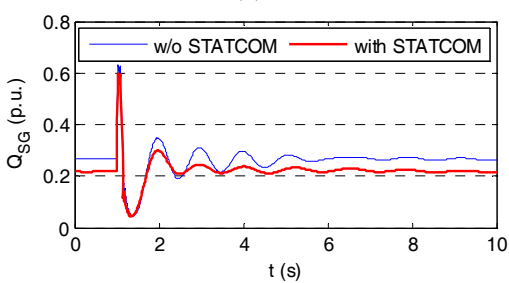

(d) $Q_{S G}$

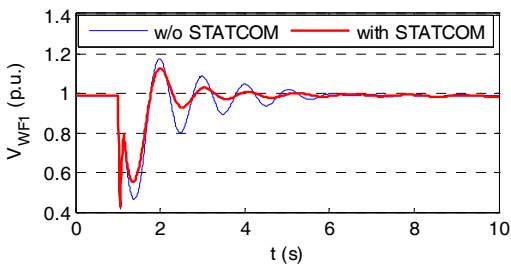

(g) $V_{W F 1}$

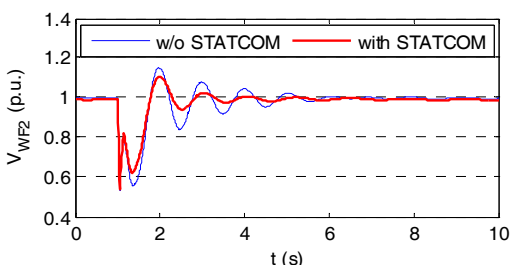

(j) $V_{W F 2}$

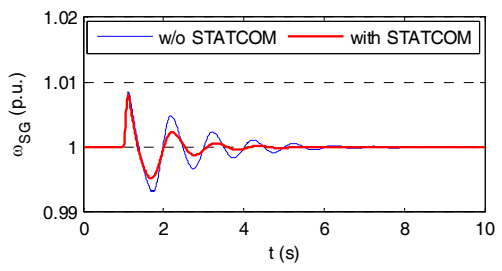

(b) $\omega_{S G}$

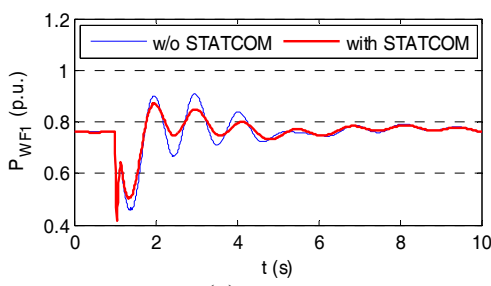

(e) $P_{W F 1}$

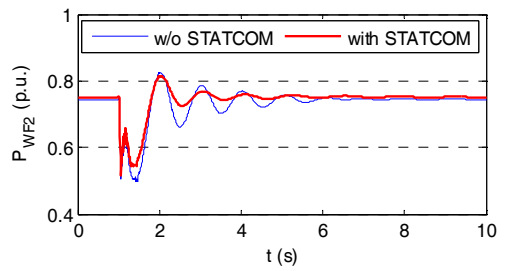

(h) $P_{W F 2}$

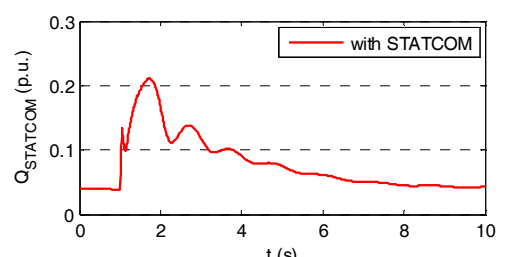

(k) $Q_{\text {STATCOM }}$

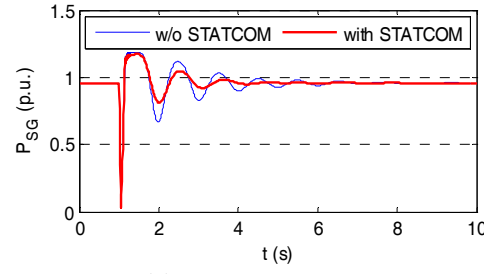

(c) $P_{S G}$

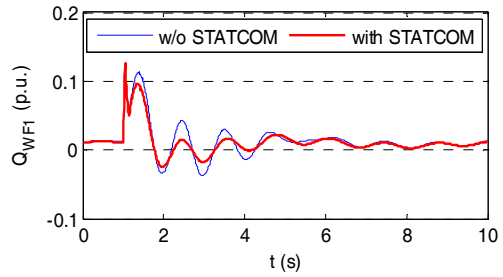

(f) $Q_{W F 1}$

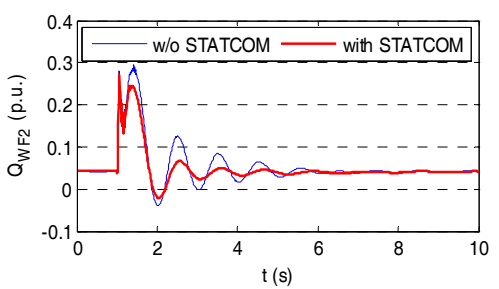

(i) $Q_{W F 2}$

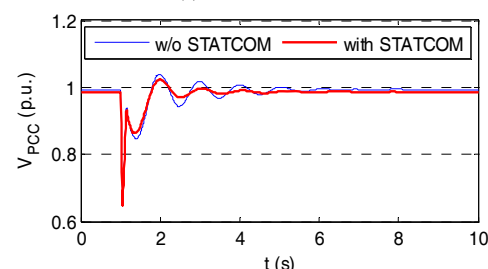

(1) $V_{\text {PCC }}$

Fig. 4. Comparative transient responses of the studied system subject to a three-phase short-circuit fault at the infinite bus.

\section{Conclusion}

This paper has presented the stability-improvement results of a SG-based OMIB system with a hybrid DFIG-based and PMSG-based OWF using a STATCOM connected to the PCC of the studied system. The eigenvalue technique has been employed to demonstrate that the damping of the mechanical mode of the SG can be improved by the proposed STATCOM. Transient responses of the studied system subject to a severe three-phase short-circuit fault at the power grid have demonstrated the proposed STATCOM can offer adequate damping characteristics to stabilize the inherent mechanical-mode oscillations of the studied OMIB system.

\section{Acknowledgements}

The authors would like to thank the financial support from National Science of Council (NSC) of Taiwan under Grant NSC 101-ET-E-006-005-ET, Grant NSC 101-3113-P-006-014, and Grant NSC-1013113-E-006-013

\section{References}

[1] Cartwright P, Holdsworth L, Ekanayake JB, Jenkins N. Coordinated voltage control strategy for a doubly-fed induction generator (DFIG)-based wind farm. IEE Proc.-Gener. Transm. Distrib, 2004; 151(4):4 495-502.

[2] Chen Z, Spooner E. A modular, permanent-magnet generator for variable speed wind turbines. In: Proc.of Seventh International Conference on Electrical Machines and Drives, 1995:453-457.

[3] Wu F, Zhang XP, Ju P. Small signal stability analysis and control of the wind turbine with the direct-drive permanent magnet generator integrated to the grid. Electric Power Systems Research, 2009; 79(12):1661-1667. 
[4] Nishikata S, Tatsuta F. A new interconnecting method for wind turbine/generators in a wind farm and basic performances of the integrated system. IEEE Trans. Industrial Electronics, 2010; 57(2):468-475.

[5] Strachan NPW, Jovcic D. Stability of a variable-speed permanent magnet wind generator with weak AC grids. IEEE Trans. Power Delivery, 2010; 25(4):2779-2788.

[6] Muyeen SM, Takahashi R, Murata T, Tamura J. A variable speed wind turbine control strategy to meet wind farm grid code requirements. IEEE Trans. Power Systems, 2010; 25(1):331-340.

[7] Leon AE, Mauricio JM, Gomez-Exposito A, Solsona JA. An improved control strategy for hybrid wind farms. IEEE Trans. Sustainable Energy, 2010; 1(3):131-141.

[8] Zhang S, Tseng KJ, Vilathgamuwa DM, Nguyen TD, Wang XY. Design of a robust grid interface system for PMSG-based wind turbine generators. IEEE Trans. Industrial Electronics, 2011; 58(1):316-328.

[9] Uehara A, Pratap A, Goya T, Senjyu T, Yona A, Urasaki N, Funabashi T. A coordinated control method to smooth wind power fluctuations of a PMSG-based WECS. IEEE Trans. Energy Conversion, 2011; 26(2):550-558.

[10] Chong H, Huang AQ, Baran ME, Bhattacharya S, Litzenberger W, Anderson L, Johnson AL, Edris AA. STATCOM impact study on the integration of a large wind farm into a weak loop power system. IEEE Trans. Energy Conversion, 2008; 23(1):226-233.

[11] Gaztanaga H, Etxeberria-Otadui I, Ocnasu D, Bacha S. Real-time analysis of the transient response improvement of fixedspeed wind farms by using a reduced-scale STATCOM prototype. IEEE Trans. Power Systems, 2007; 22(2):658-666.

[12] Jain A, Joshi K, Behal A, Mohan N. Voltage regulation with STATCOMs: Modeling, control and results. IEEE Trans. Power Delivery, 2006; 21(2):726-735.

[13] P. Kundur. Power System Stability and Control. New York: McGraw-Hill, Inc.; 1994.

[14] Anderson PM, Bose A. Stability simulation of wind turbine system. IEEE Trans. Power Apparatus and Systems, 1983; 102(12):3791-3795.

[15] Heier S, Waddington R. Grid Integration of Wind Energy Conversion Systems. New York: John Wiley \& Sons; 1998.

[16] Muyeen SM, Ali MH, Takahashi R, Murata T, Tamura J, Tomaki Y, Sakahara A, Sasano E. Transient stability analysis of wind generator system with the consideration of multi-mass shaft model. In: Proc. of International Conference on Power Electronics and Drives Systems, 2006:511-516.

[17] CIGRE, Modeling New Forms of Generation and Storage, TF.01.10, Fifth draft; 2000.

[18] Hughes FM, Anaya-Lara O, Jenkins N, Strbac G. Control of DFIG-based wind generation for power network support. IEEE Trans. Power Systems, 2005; 20(4):1958-1966.

[19] Kayıkçı M, Milanović JV. Reactive power control strategies for DFIG-based plants. IEEE Trans. Energy Conversion 2007, 22(2):389-396.

[20] Wang L, Hsiung CT. Dynamic stability improvement of an integrated grid-connected offshore wind farm and marine-current farm using a STATCOM. IEEE Trans. Power Systems, 2011; 26(2):690-698. 